Article

\title{
Preparation and Characterization of Graphene Oxide-Modified Sapium sebiferum Oil-Based Polyurethane Composites with Improved Thermal and Mechanical Properties
}

\author{
Guiying $\mathrm{Wu}^{\dagger}$, Xiaoling $\mathrm{Xu}^{\dagger}{ }^{\dagger}$, Xin He and Yunjun Yan * (1) \\ Key Laboratory of Molecular Biophysics of the Ministry of Education, College of Life Science and Technology, \\ Huazhong University of Science and Technology, Wuhan 430074, China; wuguiying@hust.edu.cn (G.W.); \\ xuxiaoling@hust.edu.cn (X.X.); n785888@163.com (X.H.) \\ * Correspondence: yanyunjun@hust.edu.cn; Tel.: +86-27-8779-2213 \\ † These authors contributed equally to this work.
}

Received: 30 December 2017; Accepted: 29 January 2018; Published: 30 January 2018

\begin{abstract}
Bio-based polyurethane (PU) composites with superior thermal and mechanical properties have received wide attention. This is due to the recent rapid developments in the PU industry. In the work reported here, novel nano-composites with graphene oxide (GO)-modified Sapium sebiferum oil (SSO)-based PU has been synthesized via in situ polymerization. GO, prepared using the improved Hummers method from natural graphene (NG), and SSO-based polyol with a hydroxyl value of $211 \mathrm{mg} \mathrm{KOH} / \mathrm{g}$, prepared by lipase hydrolysis, were used as raw materials. The microstructures and properties of GO and the nano-composites were both characterized using Fourier transform infrared spectroscopy (FTIR), Raman spectroscopy, X-ray diffraction (XRD), transmission electron microscopy (TEM), scanning electron microscopy (SEM), thermogravimetric analysis (TGA), differential scanning calorimetry (DSC), and tensile tests. The results showed that GO with its nano-sheet structure possessed a significant number of oxygen-containing functional groups at the surface. The nano-composites containing $1 \mathrm{wt} \% \mathrm{GO}$ in the PU matrix (PU1) exhibited excellent comprehensive properties. Compared with those for pure PU, the glass transition temperature $\left(T_{\mathrm{g}}\right)$ and initial decomposition temperature (IDT) of the PU1 were enhanced by 14.1 and $31.8^{\circ} \mathrm{C}$, respectively. In addition, the tensile strength and Young's modulus of the PU1 were also improved by $126 \%$ and $102 \%$, respectively, compared to the pure PU. The significant improvement in both the thermal stability and mechanical properties for PU/GO composites was attributed to the homogeneous dispersion and good compatibility of GO with the PU matrix. The improvement in the properties upon the addition of GO may be attributable to the strong interfacial interaction between the reinforcing agent and the PU matrix.
\end{abstract}

Keywords: graphene oxide; Sapium sebiferum oil; polyurethane; nano-composites

\section{Introduction}

Polymeric nano-composites with low costs, excellent properties, and corrosion resistance derived from eco-friendly resources are extremely scarce and urgently needed in the fields of machinery fabrication, electronics, biomedicine, and the chemical industry [1,2]. In recent years, utilization of renewable resources for the synthesis of polymers has become a priority to meet the requirements of sustainable development and environment friendliness in the chemical industry [3,4].

Bio-based polyurethane (BPU) is one of the most promising polymer matrixes for composites owing to its molecular designability, structural controllability, and performance diversity $[5,6]$. 
However, polyurethane (PU) is usually made from diisocyanates and polyols originating from petroleum, which is in finite supply, and its utilization may contribute to environmental pollution.

Currently, significant attention has been focused on plant oil-based polyols, derived from soybean, sunflower, jatropha, linseed, castor, tung, palm, and Sapium sebiferum kernel oils, for the preparation of novel specific polyurethane formulations [7-9]. Compared with other plants oils, Sapium sebiferum oil (SSO) is one of the most economical oil sources for the preparation of Sapium sebiferum polyols (SSP) due to its large number of carbon-carbon double bonds and high iodine value. It is a non-food oil and can be produced on land unsuitable for farming [10]. The abundance of unsaturated bonds make the oil a desirable feedstock for the synthesis of polyols with high hydroxyl values through biochemical processes [11,12]. For this reason, using plant oil-based polyols to replace petroleum-based polyols as raw materials for the preparation of PU is a significant development, which has economic benefit and is of practical significance. However, the limited thermal stability and mechanical strength of bio-based PU materials prohibit their wide industrial application [13].

Nanomaterials with reticular, lamellar, tubular, and fibrous structures have become widely used as reinforcing agents to improve the performance of BPU composites [14,15]. Among these, graphene, a two-dimensional nanomaterial with a honeycomb lattice structure, excellent performance, and relatively low price, is an effective reinforcing agent for preparing PU composites [16,17]. Since it was discovered in 2004, graphene has received significant attention and has become a popular compound in the field of novel composites [18].

However, graphene, being neither water nor oil wettable, displays weak interactions with polymeric materials and does not disperse easily $[19,20]$. As a result, genuine composites with desirable properties cannot be generated. On the contrary, graphene oxide (GO), derived from graphene with a large number of oxygen-containing groups, has good wettability, surface activity, and reactivity [21]. Consequently, GO is a potential reinforcing agent for the development of high-performance composites. In previous studies, blends of GO and petroleum-based PU have been prepared [22-25]. In contrast, the modification of plant oil-based PU with GO has not been reported.

In this work, GO containing carboxylic acid and hydroxy groups at the surface has been prepared using an improved Hummers method and cavitated via ultrasonic exfoliation. Then, GO-modified SSO-based PU composites were prepared via in situ polymerization for the first time to generate novel nano-composites with improved properties. Therefore, the goals of this study were (1) to prepare and characterize GO; (2) to synthesize GO-modified SSO-based PU nano-composites; and (3) to demonstrate the reinforcement effect of $\mathrm{GO}$ on the nano-composites.

\section{Materials and Methods}

\subsection{Materials}

Sulfuric acid $\left(\mathrm{H}_{2} \mathrm{SO}_{4}, 98 \mathrm{wt} \%\right)$, hydrochloric acid $(\mathrm{HCl}, 37.5 \mathrm{wt} \%)$, potassium permanganate $\left(\mathrm{KMnO}_{4}\right)$, sodium nitrate $\left(\mathrm{NaNO}_{3}\right)$, hydrogen peroxide $\left(\mathrm{H}_{2} \mathrm{O}_{2}\right)$, and acetone were commercially obtained from Sinopharm Chemical Reagent Ltd., Co. (Shanghai, China). Nitrogen was purchased from Wuhan Xiangyun Gas Ltd., Co. (Wuhan, China). Natural graphite (NG) was got from Qingdao Furunda Graphite Ltd., Co. (Qingdao, China). Isophorone diisocyanate (IPDI) was bought from Aladdin Chemistry Ltd., Co. (Shanghai, China). Candida rugosa lipase was bought from Sigma-Aldrich (Shanghai, China) and used without further purification. Sapium sebiferum oil (SSO) was purchased from a refinery factory in Dawu County (Dawu, China). The SSP prepared from SSO was dried at $60{ }^{\circ} \mathrm{C}$ for $12 \mathrm{~h}$ under a vacuum to remove moisture. Other materials were of analytical grade and used without further treatment. 


\subsection{Synthesis Methods}

\subsubsection{Preparation of GO}

Exfoliated GO was synthesized by following the improved Hummers method [26,27], and treated to ultrasonic exposure. First, $1 \mathrm{~g}$ of NG flakes and $0.5 \mathrm{~g}$ of $\mathrm{NaNO}_{3}$ were dissolved in $75 \mathrm{~mL}$ of $98 \mathrm{wt} \%$ $\mathrm{H}_{2} \mathrm{SO}_{4}$ under magnetic stirring at $400 \mathrm{rpm}$ in an ice-water bath for $30 \mathrm{~min}$. $3 \mathrm{~g}$ of $\mathrm{KMnO}_{4}$ was then added gently into the solution, whereby the temperature of the solution did not exceed $20^{\circ} \mathrm{C}$. After the accomplishment of the addition, the reaction mixture was stirred continuously for $2 \mathrm{~h}$ at $35^{\circ} \mathrm{C}$. Second, $200 \mathrm{~mL}$ of deionized water was slowly added to dilute the viscous solution, which was then stirred at $98{ }^{\circ} \mathrm{C}$ for a further $12 \mathrm{~h}$. After the dilution, $3 \mathrm{~mL}$ of $\mathrm{H}_{2} \mathrm{O}_{2}(30 \mathrm{wt} \%)$ was added and allowed to react for $0.5 \mathrm{~h}$. Then, the brown precipitation (GO) was purified and washed with moderate $\mathrm{HCl}$ $(5 \%)$ and deionized water by repeated centrifugation until the solution became neutral. Thereafter, the product was dispersed in deionized water and ultrasonicated for $30 \mathrm{~min}$ until a homogeneous solution was obtained (see Scheme 1). The unexfoliated GO was then removed using centrifugation at $12,000 \mathrm{rpm}$ for $5 \mathrm{~min}$, and the as-prepared GO was dried at $40{ }^{\circ} \mathrm{C}$ at reduced pressure for later use.

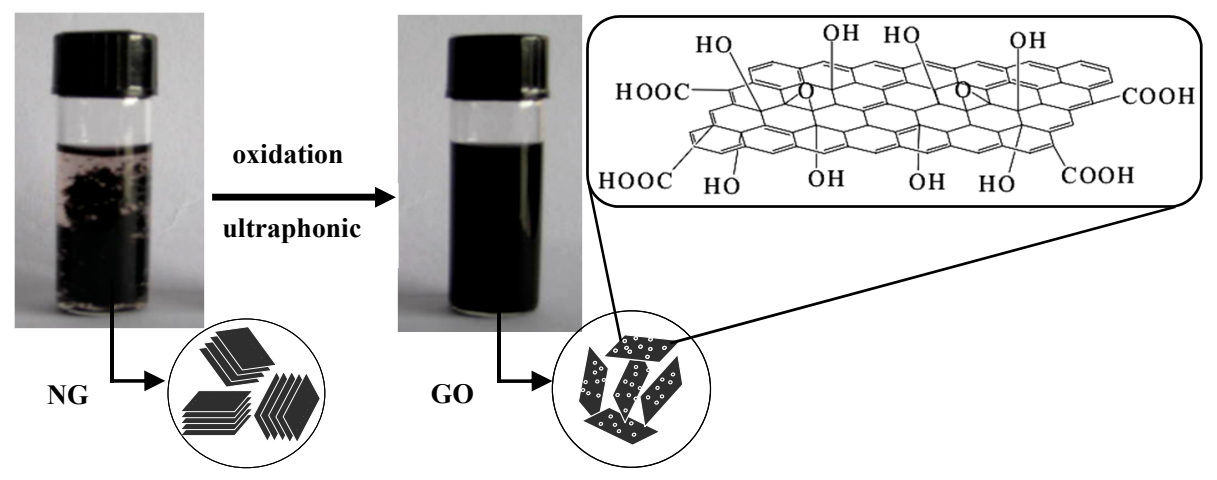

Scheme 1. Synthesis of graphene oxide (GO).

\subsubsection{Synthesis of PU and PU/GO Composites}

The SSP was synthesized based on SSO in a continuous process of epoxidation-hydroxylation and enzyme-catalyzed methods, as detailed in our previous work [28]. Simply, a two-step reaction sequence of epoxidation with peracetic acid, followed by hydroxylation with methanol, leading to a general process and avoiding unnecessary intermediate steps. Then, the aforementioned obtained ester glycerides were partially catalyzed in the presence of Candida rugosa lipase without any surfactant or organic solvent. The generated polyol product showed a hydroxyl value of $211 \mathrm{mg} \mathrm{KOH} / \mathrm{g}$, and the sample was designated as polyol-211.

SSO-based PU was further synthesized by the reaction of IPDI and polyol-211 according to a previously reported method [28-30]. The PU/GO composites were prepared via the reaction of IPDI and polyol-211 with different contents of GO at $0,0.5 \%, 1 \%$, and $1.5 \%$, named as PU0, PU0.5, PU1, and PU1.5, respectively, as shown in Scheme $2[29,30]$. GO and $20 \mathrm{~mL}$ of acetone were mixed sufficiently using sonication for $30 \mathrm{~min}$. The mixture and IPDI were allowed to react in a water-cooled condenser with a magnetic stirring at $80^{\circ} \mathrm{C}$ for $2 \mathrm{~h}$ under a nitrogen atmosphere. After that, the solution was cooled to $60^{\circ} \mathrm{C}$, and polyol-211 was added (1.1:1 mole ratio of $-\mathrm{NCO}$ to $-\mathrm{OH}$ groups) to react for $2 \mathrm{~h}$. The obtained product was degassed under vacuum for $10 \mathrm{~min}$, poured onto polytetrafluoroethylene (PTFE) molds while hot, and then heated to solidify in an oven at $60^{\circ} \mathrm{C}$ for $8 \mathrm{~h}$. 


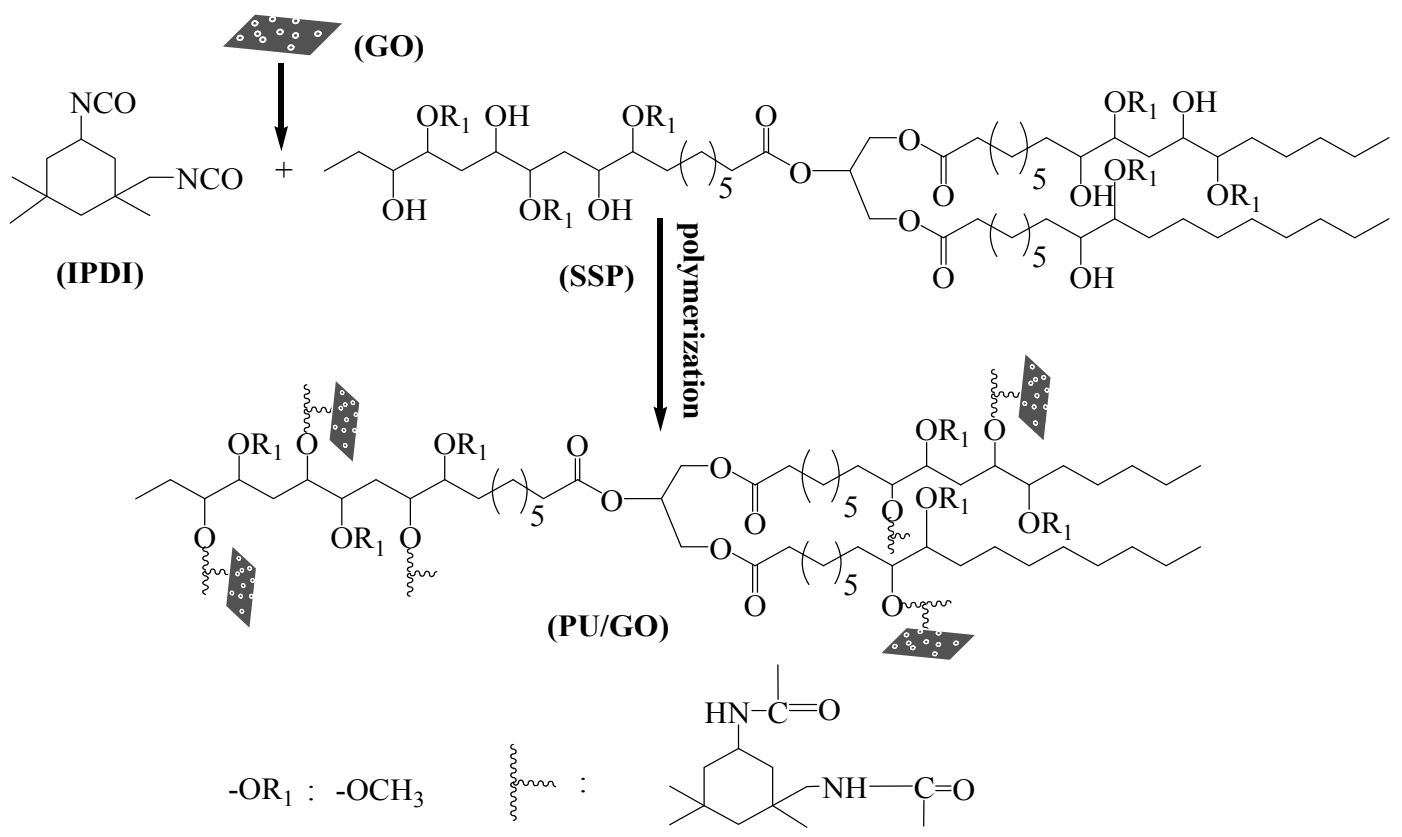

Scheme 2. Synthesis process of polyurethane (PU)/GO composites.

\subsection{Testing and Measurement}

\subsubsection{Fourier Transform Infrared Spectroscopy (FITR)}

A Fourier transform infrared spectrometer (Vertex 70 FTIR, Bruker Company, Karlsruhe, Germany) was used to examine the significant absorption spectra due to the stretching, bending, and vibration of the various types of chemical bonding present in NG, GO, PU, and PU composites at room temperature in the range of $4000-400 \mathrm{~cm}^{-1}$ at a resolution of $4 \mathrm{~cm}^{-1}$.

\subsubsection{Raman}

A laser Raman spectrometer (Vertex 70 Raman, Bruker Company, Karlsruhe, Germany) was employed to analyze the structures of NG and GO by a He-Ne $(632.8 \mathrm{~nm})$ laser using a Labram 300 system.

\subsubsection{X-ray Diffraction (XRD)}

An X-ray diffractometer (Empyrean XRD, PANalytical B.V., Almelo, The Netherlands) was used to analyze the crystallization property of NG and GO. The XRD patterns were recorded with a $\mathrm{Cu} \mathrm{K \alpha}$ radiation ( $40 \mathrm{kV}$ and $40 \mathrm{~mA}$ ) at an incident wavelength of $0.15418 \mathrm{~nm}$ in a Ni filter, with a $2 \theta$ range of $5-50^{\circ}$, a step size of $0.02^{\circ}$, and a testing time of $0.1 \mathrm{~s}$.

\subsubsection{Morphology Analysis}

Transmission electron microscopy (TEM) (Tecnai G2 20 FEI instrument, Eindhoven, Holland, The Netherlands) was designed to determine the presence of the exfoliated GO. The samples were diluted in ethanol and well dispersed for $15 \mathrm{~min}$ by sonification. A drop of the sample solution was then placed on a copper grid using a micropipette and dried before TEM observation.

The morphology of pure PU and its composites were both observed with scanning electron microscopy (Nova Nano SEM 450, FEI Company, Eindhoven, The Netherlands) at an acceleration voltage of $10 \mathrm{kV}$ and a spot size of $10 \mathrm{~nm}$. All specimens were freeze-fractured in liquid nitrogen and coated with gold before SEM observation. 


\subsubsection{Thermal Stability Analysis}

The thermal properties of the PU and PU/GO composites were analyzed with thermogravimetric analysis (Pyris1 TGA, Perkin-Elmer Instruments, Boston, MA, USA), from 30 to $600{ }^{\circ} \mathrm{C}$ at a heating rate of $10{ }^{\circ} \mathrm{C} \cdot \mathrm{min}^{-1}$ under a nitrogen atmosphere. The weight of the measured samples was about $5 \mathrm{mg}$.

The glass transition temperatures $\left(T_{\mathrm{g}}\right)$ of the PU and PU/GO composites were tested by differential scanning calorimetry (Diamond DSC, Perkin-Elmer Instruments, Boston, MA, USA) from 0 to $120^{\circ} \mathrm{C}$ with a heating rate of $10^{\circ} \mathrm{C} \cdot \mathrm{min}^{-1}$ under a nitrogen flow. Samples of approximately $5 \mathrm{mg}$ were placed in an aluminum pan for each run.

\subsubsection{Mechanical Testing}

The mechanical properties of the PU and PU/GO composites $(100 \mathrm{~mm} \times 10 \mathrm{~mm} \times 4 \mathrm{~mm})$ were examined on a CMT4104 universal testing machine (Shenzhen SANS Testing Machine Ltd., Co., Shenzhen, China) at a speed of $50 \mathrm{~mm} \cdot \mathrm{min}^{-1}$. Every specimen was measured six times, and the average value was calculated.

\section{Results and Discussion}

\subsection{Structural Characterization of $G O$}

\subsubsection{FTIR Analysis of GO}

The FTIR spectra for NG and GO are shown in Figure 1a,b, respectively. The band at $3422 \mathrm{~cm}^{-1}$ is attributed to the presence of $\mathrm{O}-\mathrm{H}$ groups on the surface of $\mathrm{NG}$ and is recognized as the tight binding of moisture restored in NG. The weak absorption at $1622 \mathrm{~cm}^{-1}$ is the characteristic of the $\mathrm{C}=\mathrm{C}$ stretching vibration between the layers of NG. For the GO spectrum(Figure 1b), the peaks at 3422, 1726, 1622, 1400,1227 and $1049 \mathrm{~cm}^{-1}$ are assigned to $\mathrm{O}-\mathrm{H}$ stretching, $\mathrm{C}=\mathrm{O}$ stretching, $\mathrm{C}=\mathrm{C}$ stretching, bending vibration of $\mathrm{O}-\mathrm{H}$ in carboxylic group, $\mathrm{C}-\mathrm{OH}$ stretching, and $\mathrm{C}-\mathrm{O}$ stretching $[31,32]$. This indicated that some of the $-\mathrm{OH}$ had been enriched on the GO surface [33]. The above results confirm the successful oxidation of NG, and GO could be successfully produced by using the improved Hummers method.

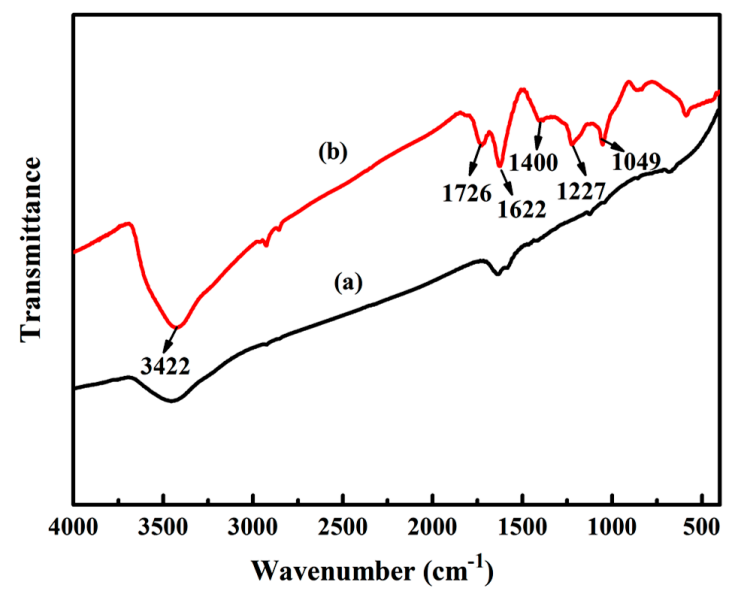

Figure 1. Fourier transform infrared spectroscopy (FITR) spectra of natural graphene (NG) (a) and GO (b).

\subsubsection{Raman Analysis of GO}

Figure 2 shows the Raman spectra of NG (a) and GO (b). GO exhibits two intensity peaks, namely, the D-bond around $1348 \mathrm{~cm}^{-1}$ and the G-bond around $1590 \mathrm{~cm}^{-1}$. In comparison, NG exhibits a weak $\mathrm{D}$ peak and an apparent $\mathrm{G}$ peak. The $\mathrm{D}$-bond is associated with the in-plane bond-stretching motion of the $\mathrm{C} \mathrm{sp}{ }^{2}$ atom pairs, which is attributed to the defects and disorders in the hexagonal graphitic layers. The G-band is concerned with the breathing modes of rings [34]. The large value of IG/ID 
(intensity of G/D peak) indicates that NG has a highly ordered architecture. For GO, the value of IG/ID decreases obviously, illustrating the irregularity structure of GO [35]. This is attributable to the structural destruction of GO, with a large number of oxygen-containing groups introduced into the graphite layers after oxidation and ultrasonic stripping treatment of NG. This hints that the random layer structure of GO may display a better compatibility in the PU matrix.

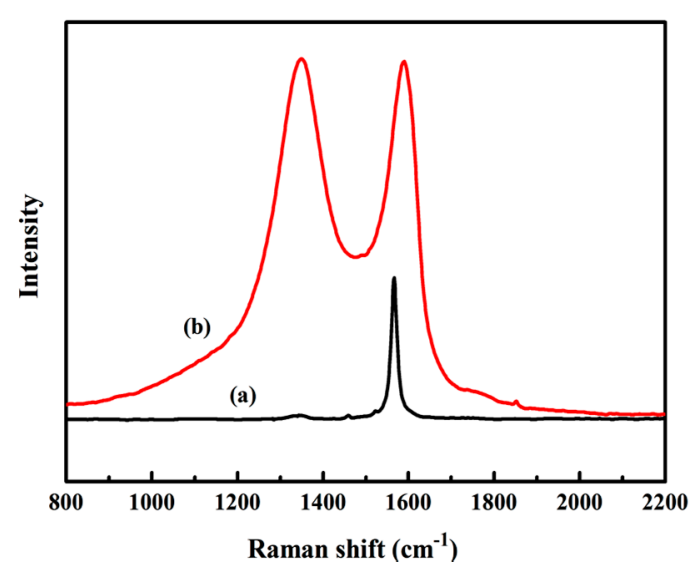

Figure 2. Raman spectra of NG (a) and GO (b).

\subsection{XRD Analysis of $G O$}

The magnitude and location of peaks in the XRD curves (Figure 3) provides very useful information for NG (a) and GO (b). NG shows a sharp and high intensity reflection peak at $2 \theta$ of $26^{\circ}$, illustrating that the microcrystalline laminar contained in NG is tidily arranged. The weak intensity and sharp reflection peak of GO at $2 \theta$ of $10^{\circ}$ is due to the introduction of functional groups, such as hydroxyls and carboxyls, during the oxidation and ultrasonic treatment. The results indicate that oxygen-containing functional groups were grafted in the layer of NG, the crystalline structure of NG was destroyed and the laminar spacing was increased [36]. This infers that the oxidation and ultrasonic treatment of NG plays effective roles in the preparation of GO. This kind of structure leads to an improvement in the compatibility and comprehensive performance of the composites.

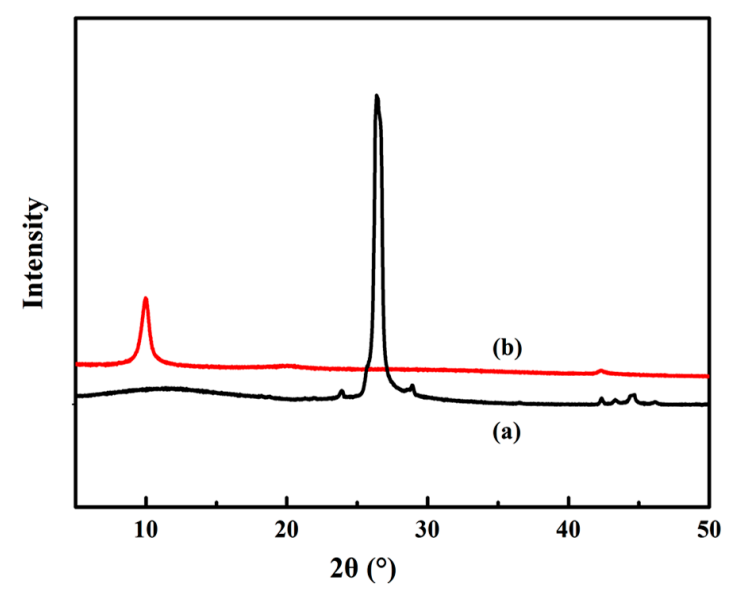

Figure 3. X-ray diffraction (XRD) patterns of NG (a) and GO (b).

\subsection{TEM Analysis of GO}

Figure 4 shows the TEM images of the morphology of GO at $0.5 \mu \mathrm{m}$ (a) and $200 \mathrm{~nm}$ (b) magnifications. GO displays a transparent and pleated sheet structure with nanoscale thickness. The pleated structure of GO possesses a lower energy state than a stretchy structure, which ensures the structural stability 
of GO [37]. In addition, the transparency indicates that the exfoliated GO exists in a single layer or a few layers. Furthermore, owing to the oxidation of NG, oxygen-containing functional groups were introduced into the surface of GO, and the orderly structure of the layers might be broken, which would weaken the intra-molecular interactions and enhance the dispersion stability.

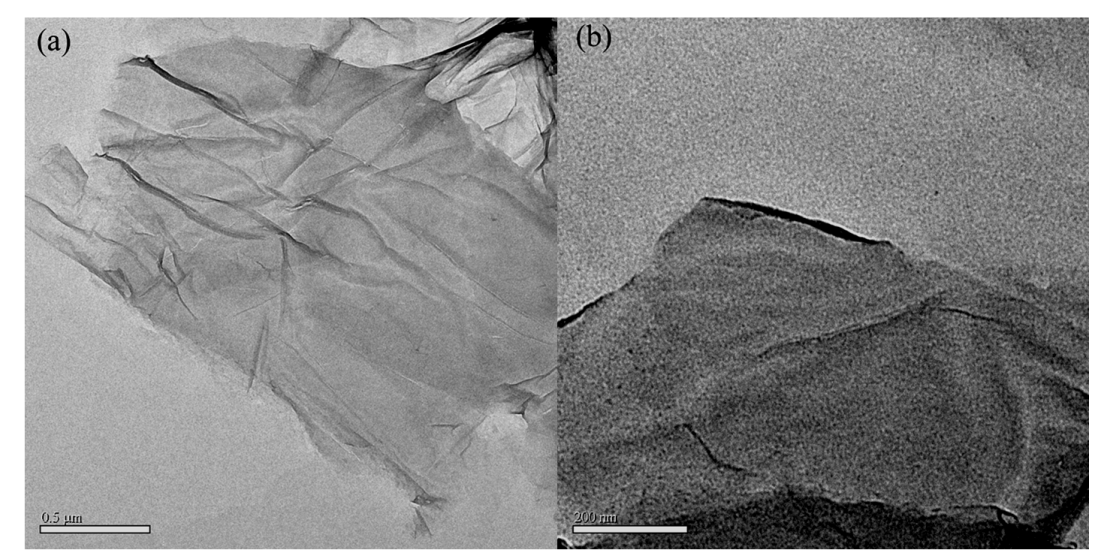

Figure 4. The transmission electron microscopy (TEM) images of GO at (a) in $0.5 \mu \mathrm{m}$ and (b) in $200 \mathrm{~nm}$ magnifications.

\subsection{Structural Characterization of PU/GO Composites}

The FTIR spectra of PU and PU/GO with different proportions of GO are presented in Figure 5. The characteristic absorption of $-\mathrm{OH}$ groups in the $\mathrm{PU}$ and $\mathrm{PU} / \mathrm{GO}$ composites is obvious at $3359 \mathrm{~cm}^{-1}$, which is shifted slightly to lower wavenumbers direction in comparison with that in GO (Figure 1b). Unexpectedly, although isocyanate groups were overdosed in the original formulation, no -NCO peak was observed at $2270 \mathrm{~cm}^{-1}$. One possible reason was that not all the $-\mathrm{OH}$ groups were accessible to react with -NCO groups due to the existence of molecular steric hindrance. The other probable cause was that the $-\mathrm{NCO}$ groups reacted with $-\mathrm{OH}$ derived from the moisture in the air [38]. In addition, the typical characteristic infrared absorption peak of PU appeared. The broad bands at 3359 and $1726 \mathrm{~cm}^{-1}$ were attributed to urethane $\mathrm{N}-\mathrm{H}$ stretching and $\mathrm{C}=\mathrm{O}$ stretching. The two peaks at 1544 and $1232 \mathrm{~cm}^{-1}$ corresponded to the $\mathrm{N}-\mathrm{H}$ in-plane and $\mathrm{C}-\mathrm{N}$ bond stretching, respectively [38]. The stretching vibration bands at 2926 and $2867 \mathrm{~cm}^{-1}$ were assigned to methyl $\left(-\mathrm{CH}_{3}\right)$ and methylene $\left(-\mathrm{CH}_{2}-\right)$ in the composites. The characteristic peaks of $\mathrm{C}-\mathrm{O}$ at $1242 \mathrm{~cm}^{-1}$ were the vibration bands of the ester bond. In general, the obtained results demonstrated that PU was successfully synthesized, with no significant difference between PU and PU/GO. In other words, the addition of GO did not introduced any new functional groups into the PU matrix.

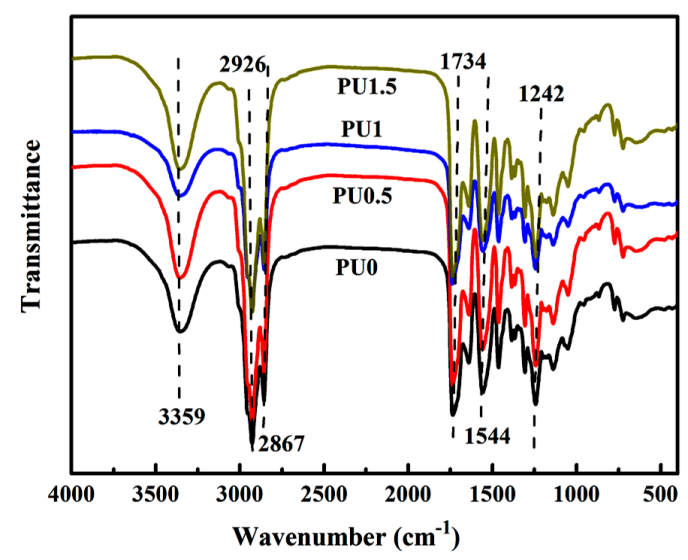

Figure 5. Fourier transform infrared spectroscopy (FTIR) spectra of PU0 and PU/GO composites. 


\subsection{Microstructure of Pure PU and PU/GO Composites}

Figure 6 shows the SEM images of the dispersion and interactions of GO in the PU matrix. As shown, the fractured surface of PU0 is smooth(Figure 6a), while the laminar folds in the images represent GO nano-sheets in the PU matrix and rough fractured surfaces displays on the PU/GO composites. A non-separated structure appears on the fracture section of the composite with GO for different mass fractions, which demonstrates that the exfoliated GO flakes can be adequately embedded into the PU matrix. When the GO is at $1 \mathrm{wt} \%$ loading (Figure $6 \mathrm{c}$ ), the fractured surface of the composite fills with GO nano-sheets and generates a tight binding and homogeneous dispersion, suggesting that good compatibility and strong interactions exist between GO and the PU matrix. A slight agglomeration and a cumulative folding surface (Figure $6 \mathrm{~d}$ ) appears at a GO loading of $1.5 \mathrm{wt} \%$, resulting in a rather poor distribution of GO in the matrix. This is probably attributed to the strong hydrophilicity and high surface free energy of GO nano-sheets when the loading is further increased. Hence, GO partially grafting on the PU matrix can provide a homogeneous dispersion, which effectively improves the overall properties of the PU/GO composites.

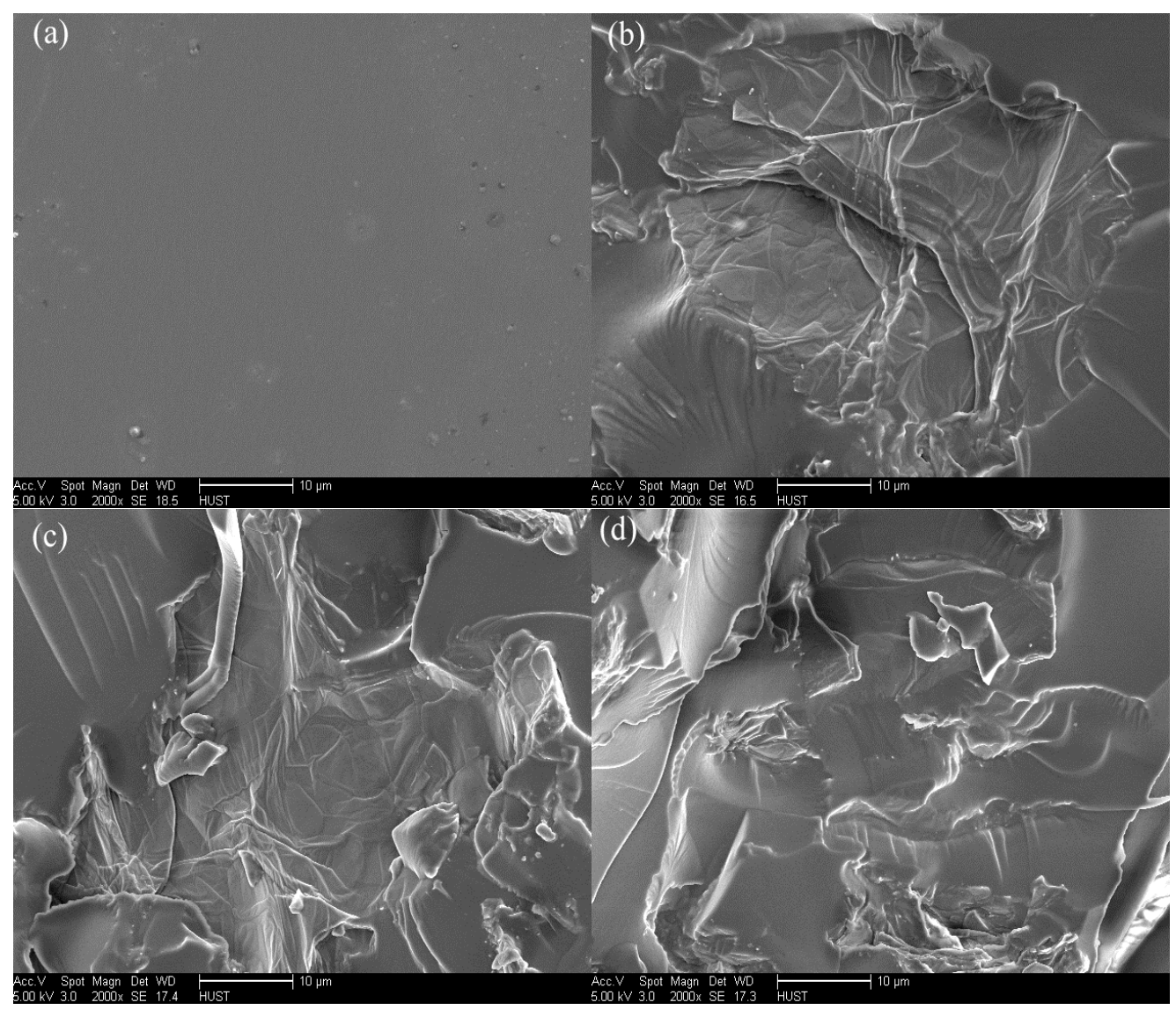

Figure 6. Scanning electron microscopy (SEM) images of PU0 (a), PU0.5 (b), PU1 (c), and PU1.5 (d) at a $10 \mu \mathrm{m}$ magnification.

\subsection{Thermal Properties of Pure PU and PU/GO Composites}

DSC experiments provided the glass transition temperature $\left(T_{\mathrm{g}}\right)$ for the pure PU and PU/GO composites. As seen in Figure 7, the $T_{\mathrm{g}}$ values of PU0, PU0.5, PU1 and PU1.5 are 60.6, 65.2, 74.7 and $69.1{ }^{\circ} \mathrm{C}$, respectively. The $T_{\mathrm{g}}$ of all PU/GO composites are higher than that of the pure PU, suggesting that GO has a significantly positive effect on the crystallization of the PU, resulting in an increase in $T_{\mathrm{g}}$. As reported in the literature, $T_{\mathrm{g}}$ represents the mobility of polymer chains and network in the matrix at 
the molecular level [39]. The increase in the value of $T_{\mathrm{g}}$ indicates a movement decrease for molecules in the matrix.

In this experiment, the well-distributed GO nanomaterial in the matrix acts as a reinforcing agent, which enhances the rigidity of the matrix and limits the free movement of the molecular chain. PU1 had a maximal value of $74.7^{\circ} \mathrm{C}$. The value of $T_{\mathrm{g}}$ for PU1.5 decreased slightly compared with that of PU1, which was due to the micro-phase separation of the PU/GO composites, resulting in part of the agglomeration owing to the overloading of GO in the matrix. This was also confirmed by the SEM images. Therefore, the well-distributed GO nano-sheets in the PU matrix can efficiently increase the value of $T_{\mathrm{g}}$.

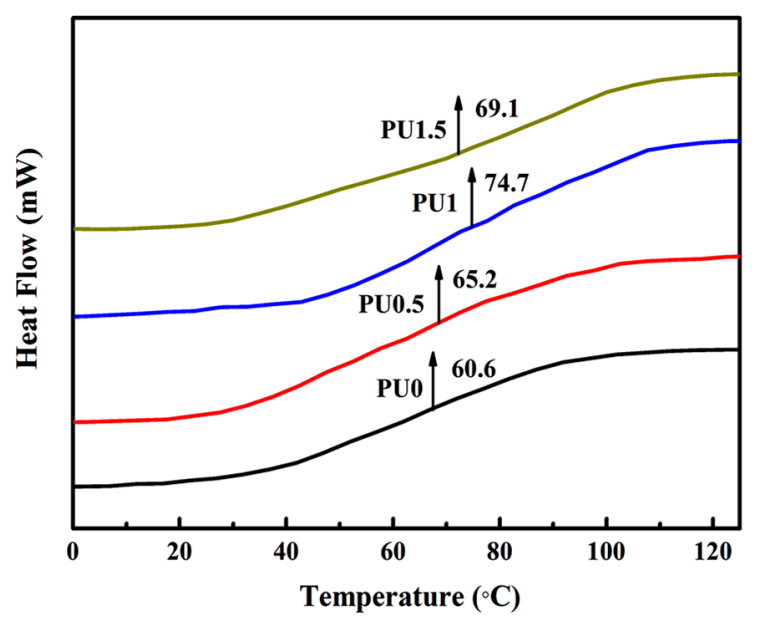

Figure 7. Differential scanning calorimetry (DSC) curves of PU0 and PU/GO composites.

Figures 8 and 9 show the TGA and DTG curves of the PU and PU/GO composites, respectively. The values of initial decomposition temperature at $5 \%$ weight loss (IDT), temperature for the maximum rate of degradation $\left(T_{\max }\right.$ ) and residues are listed in Table 1. As seen in the TGA curves, the same trend of weight loss displays for all samples. A small weight loss at $100{ }^{\circ} \mathrm{C}$ was due to the decomposition of bound moisture, low molecules organic solvents and impurity. The other two obvious weight loss processes are the decomposition of the soft segment at the range of $340-380{ }^{\circ} \mathrm{C}$ and the decomposition of the hard segment at the range of $420-450{ }^{\circ} \mathrm{C}$. Thermal degradations of the pure PU and PU/GO composites take place at two stages, corresponding to the thermodynamic incompatibility of the two segments of the PU matrix [40].

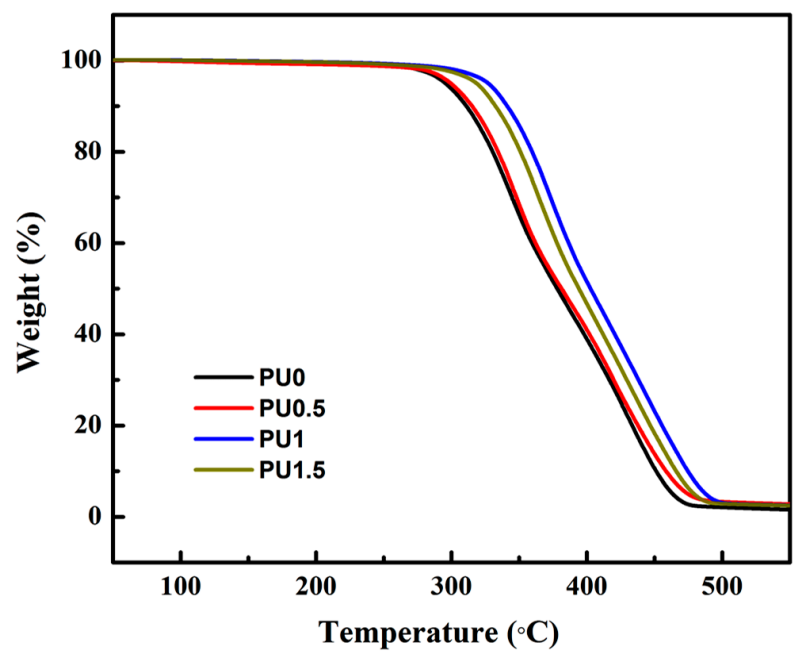

Figure 8. Thermogravimetric analysis (TGA) curves of PU0 and PU/GO composites. 


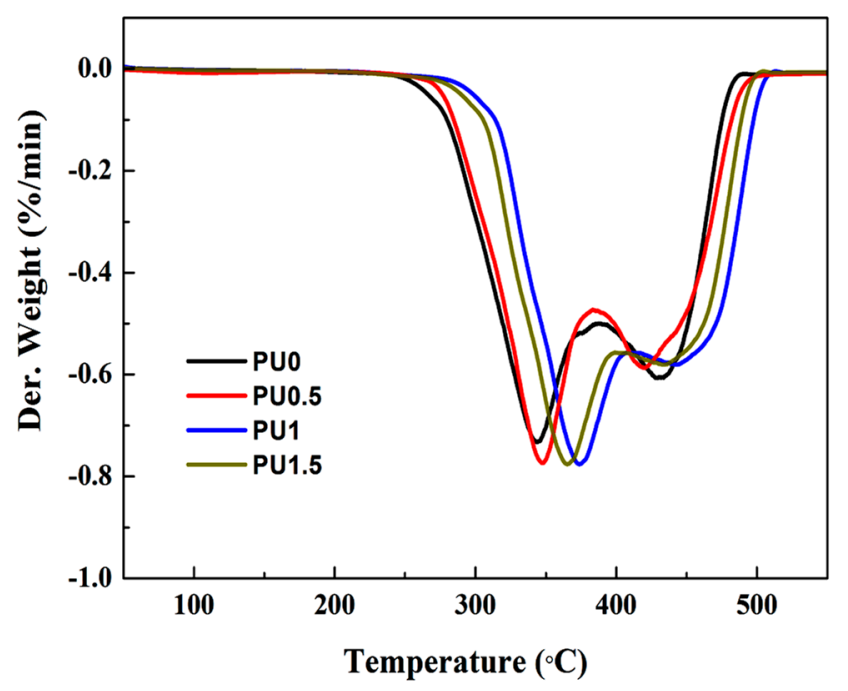

Figure 9. Differential thermal gravity (DTG) curves of PU0 and PU/GO composites.

The IDT of PU0 is $294.3^{\circ} \mathrm{C}$, which is lower than that of PU/GO composites (Table 1). The $T_{\max }$ for both of the two stages of the PU/GO composites is also much higher than that of PU0. As expected, the incorporation of $1 \mathrm{wt} \% \mathrm{GO}$ in the PU matrix displays the best thermal stability of the composites. PU1 displays the highest IDT and two step of $T_{\max }$, which delayed by $31.8,33.4$ (1st) and $12.9^{\circ} \mathrm{C}(2 \mathrm{nd})$ at the side of PU0. It is attributable to the homogeneous dispersion and stronger interfacial interactions of GO in the PU matrix. The residues of the PU and PU/GO composites at $550{ }^{\circ} \mathrm{C}$ are about $2 \mathrm{~g}$ due to the carbonization. These results suggest that an appropriate loading of GO in the PU matrix can enhance the thermal stability of PU/GO composites. It can be ascribed to the numerous oxygenated active groups randomly distributed on the surface of GO, which play effective roles in undergoing chemical reactions and intermolecular interactions with the matrix. As a result, the networks were formed that limit the movement of the molecular chain of PU. Alternatively, the overloading nano-sheets of GO can generate an irreversible aggregation in some way, which decreases the thermal stability of the composites.

Table 1. Dynamic mechanical analysis (TGA) and differential thermal gravity (DTG) results for PU0 and PU/GO composites.

\begin{tabular}{ccccc}
\hline \multirow{2}{*}{ Sample } & \multirow{2}{*}{ IDT $\left({ }^{\circ} \mathbf{C}\right)$} & \multicolumn{2}{c}{$\mathbf{T}_{\text {max }}$} & Residue at $\mathbf{5 5 0}{ }^{\circ} \mathbf{C}(\%)$ \\
\cline { 3 - 4 } & & 1st Step $\left({ }^{\circ} \mathbf{C}\right)$ & 2nd Step $\left({ }^{\circ} \mathbf{C}\right)$ & 1.8 \\
PU0 & 294.3 & 341.8 & 429.7 & 2.1 \\
PU0.5 & 297.6 & 347.3 & 419.2 & 2.2 \\
PU1 & 326.1 & 375.2 & 442.6 & 2.3 \\
PU1.5 & 315.2 & 365.1 & 436.8 & \\
\hline
\end{tabular}

\subsection{Mechanical Properties of Pure PU and PU/GO Composites}

The mechanical properties of PU/GO with different contents of GO were investigated by tensile testing. The tensile strength, elongation at break and Young's modulus are listed in Table 2. It shows that the tensile strength and Young's modulus of PU0 are lower than those of the PU/GO composites, while a slight decrease occurs for the elongation at break of the PU/GO composites. PU1 has the highest tensile strength and Young's modulus among the composites, and they are 28.3 and $45.1 \mathrm{MPa}$, which were, respectively, increased by $126 \%$ and $102 \%$ in comparison with PU0. Further addition of GO (1.5 wt \%) into the PU matrix causes a decrease in tensile strength and Young's modulus, which is presumably due to the partial agglomeration phenomenon of GO. It is demonstrated that it was 
the construction of nano-sheets of GO that are responsible for the enhanced effect. The probable mechanism is that large numbers of oxygen-containing groups are exposed on the GO surface, leading to strong covalent bonding forces and interfacial interactions between $\mathrm{GO}$ and $\mathrm{PU}$, which can facilitate the generation of a cross-linked polymer network [17]. However, the elongation at break of the composites decreases with increasing GO content. The possible cause is the high cross-linkage between the GO and PU matrix, which reduces the toughness and malleability of the composite. These results are also in accordance with the results of $T_{\mathrm{g}}$ and $T_{\max }$. Therefore, the addition of a proper amount of GO into the PU matrix can significantly improve its $T_{\mathrm{g}}$, thermal stability and mechanical properties.

Table 2. Mechanical properties of PU0 and PU/GO composites.

\begin{tabular}{cccc}
\hline & Tensile strength (MPa) & Elongation at break (\%) & Young's modulus (MPa) \\
\hline PU0 & $12.5 \pm 0.6$ & $168.3 \pm 12.3$ & $22.3 \pm 1.4$ \\
PU0.5 & $19.2 \pm 0.8$ & $152.2 \pm 12.5$ & $28.4 \pm 1.5$ \\
PU1 & $28.3 \pm 1.9$ & $143.5 \pm 11.4$ & $45.1 \pm 4.1$ \\
PU1.5 & $24.7 \pm 1.6$ & $134.6 \pm 10.8$ & $35.3 \pm 3.2$ \\
\hline
\end{tabular}

\section{Conclusions}

In this work, GO and oil-based PU/GO nano-composites were synthesized and characterized. The FTIR, XRD, TEM, and Raman spectroscopy results showed that GO had been successfully prepared using the improved Hummers method and partly introduced into the PU matrix via in situ polymerization. After oxidation and ultrasonic treatment, the amount of oxygen functional groups on the GO surface was greatly increased. GO exhibited a nano-sheet structure and was used as a reinforcing agent for PU improvement. The structure-property relationships with different contents of GO were illustrated. SEM analysis shows that the addition of $1 \mathrm{wt} \%$ GO displays the best dispersion inside the PU matrix and is the most effective to improve the thermal and mechanical properties of the PU/GO composite. The IDT and $T_{\mathrm{g}}$ of PU1 compared with PU0 enhances at 31.8 and $14.1{ }^{\circ} \mathrm{C}$, respectively. In the meantime, the tensile strength and Young's modulus of PU1 are also enhanced by $126 \%$ and $102 \%$. The marked improvement of thermal and mechanical properties of the PU/GO composites is due to the good compatibility and the presence of strong interfacial interaction between GO and PU matrix. Moreover, the novel oil-based PU/GO composites in this study may have promising and comprehensive applications in the fields of machinery, electronics, biomedicine, and the chemical industry.

Acknowledgments: This work is financially supported by the National Natural Science Foundation of China (Nos. 31070089, 31170078 and J1103514), the National High Technology Research and Development Program of China (2011AA02A204, 2013AA065805), the Fundamental Research Funds for HUST (Nos. 2014NY007, 2017KFXKJC010, 2017KFTSZZ001), and the Project of Post-doctoral Science and Technology Activities in Hubei Province (0106170092). Many thanks are indebted to Analytical and Testing Center of HUST for their valuable assistances in FTIR, Raman, SEM, TEM, TGA, and DSC measurements.

Author Contributions: Guiying Wu and Yunjun Yan conceived and designed the experiments; Guiying Wu performed the experiments; Xiaoling $\mathrm{Xu}$ and $\mathrm{Xin}$ He assisted in part of the experiments, testing and analyzed the data; Xiaoling Xu wrote the paper. Xiaoling Xu and Yunjun Yan contributed to the revision and proofreading of the manuscript.

Conflicts of Interest: The authors declare no conflict of interest.

\section{References}

1. Cheng, C.C.; Liao, Z.S.; Huang, J.J.; Huang, S.Y.; Fan, W.L. Incorporation of supramolecular polymerfunctionalized graphene: Towards the development of bio-based high electrically conductive polymeric nanocomposites. Compos. Sci. Technol. 2017, 148, 89-96. [CrossRef]

2. Leng, W.Q.; Li, J.H.; Cai, Z.Y. Synthesis and Characterization of Cellulose Nanofibril-Reinforced Polyurethane Foam. Polymers 2017, 9, 597. [CrossRef] 
3. Luo, W.K.; Qin, J.X.; Xiao, M.; Han, D.M.; Wang, S.J.; Meng, Y.Z. Synthesis of aliphatic carbonate macrodiols and their application as sustainable feedstock for polyurethane. ACS Omega 2017, 2, 3205-3213. [CrossRef]

4. Pielichowska, K.; Bieda, J.; Szatkowski, P. Polyurethane/graphite nano-platelet composites for thermal energy storage. Renew. Energy 2016, 91, 456-465. [CrossRef]

5. Kucińska-Lipka, J.; Gubanska, L.; Skwarska, A. Microporous polyurethane thin layer as a promising scaffold for tissue engineering. Polymers 2017, 9, 277. [CrossRef]

6. Usman, A.; Zia, K.M.; Zuber, M.; Tabasum, S.; Rehman, S.; Zia, F. Chitin and chitosan based polyurethanes: A review of recent advances and prospective biomedical applications. Int. J. Biol. Macromol. 2016, 86, 630-645. [CrossRef] [PubMed]

7. Zhang, C.Q.; Garrison, T.F.; Madbouly, S.A.; Kessler, M.R. Recent advances in vegetable oil-based polymers and their composites. Prog. Polym. Sci. 2017, 71, 91-143. [CrossRef]

8. Das, S.; Pandey, P.; Mohanty, S.; Nayak, S.K. Evaluation of biodegradability of green polyurethane/nanosilica composite synthesized from transesterified castor oil and palm oil based isocyanate. Int. Biodeterior. Biodegrad. 2017, 117, 278-288. [CrossRef]

9. Tenorio-Alfonso, A.; Sánchez, M.C.; Franco, J.M. Preparation, Characterization and Mechanical Properties of Bio-Based Polyurethane Adhesives from Isocyanate-Functionalized Cellulose Acetate and Castor Oil for Bonding Wood. Polymers 2017, 9, 132. [CrossRef]

10. Liu, H.J.; Li, C.; Sun, X.S. Soy-oil-based waterborne polyurethane improved wet strength of soy protein adhesives on wood. Int. J. Adhes. Adhes. 2017, 73, 66-74. [CrossRef]

11. Atabani, A.E.; Silitonga, A.S.; Ong, H.C.; Mahlia, T.M.I.; Masjuki, H.H.; Badruddin, I.A.; Fayaz, H. Non-edible vegetable oils: A critical evaluation of oil extraction, fatty acid compositions, biodiesel production, characteristics, engine performance and emissions production. Renew. Sustain. Energy Rev. 2013, 18, 211-245. [CrossRef]

12. Li, Q.; Yan, Y.J. Production of biodiesel catalyzed by immobilized pseudomonas cepacia lipase from Sapium sebiferum oil in micro-aqueous phase. Appl. Energy 2010, 87, 3148-3154. [CrossRef]

13. Jaganathan, S.K.; Mani, M.P.; Ismail, A.F.; Ayyar, M. Manufacturing and Characterization of Novel Electrospun Composite Comprising Polyurethane and Mustard Oil Scaffold with Enhanced Blood Compatibility. Polymers 2017, 9, 163. [CrossRef]

14. Patel, D.K.; Singh, R.K.; Singh, S.K.; Aswal, V.K.; Rana, D.; Ray, B.; Maiti, P. Graphene as a chain extender of polyurethanes for biomedical applications. RSC Adv. 2016, 6, 58628-58640. [CrossRef]

15. Jiang, S.; Li, Q.F.; Wang, J.W.; He, Z.L.; Zhao, Y.H.; Kang, M.Q. Multiscale graphene oxide-carbon fiber reinforcements for advanced polyurethane composites. Compos. A 2016, 87, 1-9. [CrossRef]

16. Kaur, G.; Adhikari, R.; Cass, P.; Bown, M.; Evans, M.D.M.; Vashi, A.V.; Gunatillake, P. Graphene/ polyurethane composites: Fabrication and evaluation of electrical conductivity, mechanical properties and cell viability. RSC Adv. 2015, 5, 98762-98772. [CrossRef]

17. Jing, Q.F.; Liu, W.S.; Pan, Y.Z.; Silberschmidt, V.V.; Li, L.; Dong, Z.L. Chemical functionalization of graphene oxide for improving mechanical and thermal properties of polyurethane composites. Mater. Des. 2015, 85, 808-814. [CrossRef]

18. Novoselov, K.S.; Geim, A.K.; Morozov, S.V. Electric field effect in atomically thin carbon films. Science 2004, 306, 666-669. [CrossRef] [PubMed]

19. Lee, C.; Wei, X.D.; Kysar, J.W.; James, H. Measurement of the elastic properties and intrinsic strength of monolayer graphen. Science 2008, 321, 385-388. [CrossRef] [PubMed]

20. Nair, R.R.; Blake, P.; Grigorenko, A.N.; Novoselov, K.S.; Booth, T.J.; Stauber, T.; Peres, N.M.R.; Geim, A.K. Fine structure constant defines visual transparency of graphene. Science 2008, 320, 1308. [CrossRef] [PubMed]

21. Dikin, D.A.; Sasha, S.; Zimney, E.J.; Piner, R.D.; Dommett, G.H.B.; Evmenenko, G.; Nguyen, S.T.; Ruoff, R.S. Preparation and characterization of graphene oxide paper. Nature 2007, 448, 457-460. [CrossRef] [PubMed]

22. Huang, Y.L.; Baji, A.; Tien, H.W.; Yang, Y.K.; Yang, S.Y.; Wu, S.Y.; Ma, C.C.; Liu, H.Y.; Mai, Y.W. Self-assembly of silver-graphene hybrid on electrospun polyurethane nanofibers as flexible transparent conductive thin films. Photochem. Photobiol. 2012, 50, 3473-3481. [CrossRef]

23. Li, Y.T.; Lian, H.Q.; Hu, Y.N.; Chang, W.; Cui, X.G.; Liu, Y. Enhancement in mechanical and shape memory properties for liquid crystalline polyurethane strengthened by graphene oxide. Polymers 2016, 8, 236. [CrossRef] 
24. Suen, M.C.; Gu, J.H.; Lee, H.T. In situ polymerisation and characteristic properties of the waterborne grapheneoxide/poly(siloxane-urethane)s nanocomposites. Polym. Bull. 2017, 74, 4921-4942. [CrossRef]

25. Al-Attabi, N.Y.; Kaur, G.; Adhikari, R. Preparation and characterization of highly conductive polyurethane composites containing graphene and gold nanoparticles. J. Mater. Sci. 2017, 52, 11774-11784. [CrossRef]

26. Hummers, W.S.; Offeman, R.E. Preparation of graphitic oxide. J. Am. Chem. Soc. 1958, 80, 1339. [CrossRef]

27. Marcano, D.C.; Kosynkin, D.V.; Berlin, J.M.; Sinitskii, A.; Sun, Z.Z.; Slesarev, A.; Alemany, L.B.; Lu, W.; Tour, J.M. Improved synthesis of graphene oxide. ACS Nano 2010, 4, 4806-4814. [CrossRef] [PubMed]

28. Wu, G.Y.; He, X.; Yan, Y.J. Lipase-catalyzed modification of natural Sapium sebiferum oil-based polyol for synthesis of polyurethane with improved properties. RSC Adv. 2017, 7, 1504-1512. [CrossRef]

29. Wu, G.Y.; He, X.; Xu, L.; Zhang, H.J.; Yan, Y.J. Synthesis and characterization of biobased polyurethane $/ \mathrm{SiO}_{2}$ nanocomposites from natural Sapium sebiferum oil. RSC Adv. 2015, 5, 27097-27106. [CrossRef]

30. Wu, G.Y.; Fan, Y.L.; He, X.; Yan, Y.J. Bio-polyurethanes from Sapium sebiferum oil reinforced with carbon nanotubes: Synthesis, characterization and properties. RSC Adv. 2015, 5, 80893-80900. [CrossRef]

31. Si, Y.; Samulski, E.T. Synthesis of Water Soluble Graphene. Nano Lett. 2008, 8, 1679-1682. [CrossRef] [PubMed]

32. Hilder, M.; Winther-Jensen, O.; Winther-Jensen, B.; MacFarlane, D.R. Graphene/zinc nano-composites by electrochemical co-deposition. Phys. Chem. Chem. Phys. 2012, 14, 14034-14040. [CrossRef] [PubMed]

33. Ramezanzadeh, B.; Ghasemi, E.; Mahdavian, M.; Changizi, E.; Mohamadzadeh Moghadam, M.H. Covalentlygrafted graphene oxide nanosheets to improve barrier and corrosion protection properties of polyurethane coatings. Carbon 2015, 93, 555-573. [CrossRef]

34. Kim, J.; Jeon, J.H.; Kim, H.J.; Lim, H. Durable and water-floatable ionic polymer actuator with hydrophobic and asymmetrically laser-scribed reduced graphene oxide paper electrodes. ACS Nano 2014, 8, 2986-2997. [CrossRef] [PubMed]

35. Pant, H.R.; Pokharel, P.; Joshi, M.K.; Adhikari, S.; Kim, H.J.; Park, C.H.; Kim, C.S. Processing and characterization of electrospun graphene oxide/polyurethane composite nanofibers for stent coating. Chem. Eng. J. 2015, 270, 336-342. [CrossRef]

36. Zhou, Y.; Liu, X.D.; Sheng, D.K.; Lin, C.H.; Ji, F.; Dong, L.; Xu, S.B.; Wu, H.H.; Yang, Y.M. Graphene oxide/polyurethane-based solid-solid phase change materials with enhanced mechanical properties. Thermochim. Acta 2017, 658, 38-64. [CrossRef]

37. Zhu, Y.W.; Murali, S.; Cai, W.W.; Li, X.S.; Suk, J.W.; Potts, J.R.; Ruoff, R.S. Graphene and graphene oxide: Synthesis, properties, and applications. Adv. Mater. 2010, 22, 3906-3924. [CrossRef] [PubMed]

38. Strankowski, M.; Włodarczyk, D.; Piszczyk, Ł.; Strankowska, J. Polyurethane nanocomposites containing reduced graphene oxide, FTIR, Raman, and XRD Studies. J. Spectrosc. 2016, 2016. [CrossRef]

39. Tien, Y.I.; Wei, K.H. The effect of nano-sized silicate layers from montmorillonite on glass transition, dynamic mechanical, and thermal degradation properties of segmented polyurethane. J. Appl. Polym. Sci. 2002, 86, 1741-1748. [CrossRef]

40. Liu, X.; Xu, K.; Liu, H.; Cai, H.L.; Su, J.X.; Fu, Z.E.; Guo, Y.; Chen, M.C. Preparation and properties of waterborne polyurethanes with natural dimer fatty acids based polyester polyol as soft segment. Prog. Org. Coat. 2011, 72, 612-620. [CrossRef]

(C) 2018 by the authors. Licensee MDPI, Basel, Switzerland. This article is an open access article distributed under the terms and conditions of the Creative Commons Attribution (CC BY) license (http://creativecommons.org/licenses/by/4.0/). 